\title{
¿TODOS PROPIETARIOS?: DE LA IMPUGNACIÓN DE LA PROPIEDAD PRIVADA EN LA UTOPÍA MOREANA AL DISTRIBUTISMO CHESTERTONIANO ${ }^{1}$
}

\author{
Mario Ramos Vera \\ (Universidad Pontificia de Comillas ICAI-ICADE, Madrid)
}

\section{RESUMEN}

La utopía, con su carga de multidimensionalidad y densidad polisémica, ha vuelto frecuentemente su mirada a la propiedad privada por su condición estructural de elemento generador de conflictos y desigualdades. En este sentido, la Utopía del canciller y santo católico Tomás Moro plantearía el argumento de la injusta distribución de la tierra y los bienes materiales como origen primigenio de los males sociales. Paradójicamente, Gilbert Keith Chesterton, uno de los admiradores más célebres de Moro, vertebraría una utopía medievalizante caracterizada por defender antes la extensión del señorío de uso de dicha propiedad que por plantear su abolición. Esta oferta utópica de signo contrario a la utopía moreana sería conocida como distributismo. En este artículo se intenta acreditar que la propiedad privada resulta un elemento esencial para analizar la utopía chestertoniana, sustentada en el fundamento metafísico y trascendente de su antropología y filosofía política, que defendería la idea de "todos propietarios".

PALABRAS CLAVE: utopía, distopía, conservadurismo, propiedad privada, colectivismo.

\section{ALL OWNERS? FROM THE IMPUGNATION OF PRIVATE PROPERTY IN THE MOREAN UTOPIA TO CHESTERTONIAN DISTRIBUTISM}

\begin{abstract}
Utopia, with its multidimensionality and polysemous density, has frequently turned its attention to private property because of its structural condition as an element that generates conflicts and inequalities. In this sense, the Utopia of the chancellor and

\footnotetext{
1 Una versión preliminar de este texto fue presentado el 16 de diciembre de 2016 como ponencia en el Congreso internacional 500 años de Utopía: lecturas de Tomás Moro, que tuvo lugar en la Universidad Autónoma de Madrid. Pude beneficiarme de los comentarios del resto de participantes, a quienes quiero agradecer públicamente sus pertinentes sugerencias - especialmente al profesor Juan Pro-.
} 
saint of Catholic Church Thomas More would raise the argument of the unjust distribution of land and material goods as the original source of social evils. Paradoxically, Gilbert Keith Chesterton, one of the most celebrated admirers of Moro, would vertebrate a medievalizing utopia characterized by defending the extension of the lordship to use that property to raise its abolition. This utopian offer of a sign contrary to the Utopian utopia would be known as distributism. In this article we will try to prove that private property is an essential element to analyze the chestertonian utopia, based on the metaphysical and transcendent foundation of his anthropology and political philosophy, that would defend the idea of "all owners."

KEYWORDS utopia, dystopia, conservatism, private property, collectivism

\section{INTRODUCCIÓN}

Cada utopía responde a un escenario y a unos problemas propios de su época. En este sentido, las utopías han tratado de dar respuesta a cuestiones políticas, religiosas, arquitectónicas o medioambientales, por mencionar sólo algunos ejemplos. Así, las reflexiones sobre el orden de la perfección y el ideal de una sociedad ajena al conflicto se caracterizarían por articular respuestas imaginativas y posibles a controversias antropológicas, éticas y políticas. Paradójicamente, encontramos que los mayores pensadores utópicos habrían sido grandes realistas que desarrollaron penetrantes reflexiones sobre su época ${ }^{2}$. En sus utopías habrían diseñado intuitivamente esquemas y prototipos de perfección tras llevar a su máxima expresión -o a su impugnación- instituciones como la familia, el gobierno representativo o, especialmente, la propiedad privada.

Centraremos nuestra atención en la propiedad. Ya desde tiempos de Aristófanes, Faleas de Calcedonia, Hipódamo de Mileto y la República de Platón, el derecho a poseer, utilizar, enajenar, consumir o destruir una cosa se ha erigido en centro privilegiado de atención por parte del pensamiento utópico ${ }^{3}$. La propiedad, como sabemos, queda sujeta a condiciones y admite diversos grados en su ejercicio. Por esta razón podemos distinguir entre: (a) propiedad común o colectiva; (b)

${ }^{2}$ Frank E. Manuel y Fritzie P. Manuel, Utopian Thought in the Western World (Cambridge: The Belknap Press of Harvard University Press, 1979), 21-24 y 28.

${ }^{3}$ Pedro Barceló y David Hernández de la Fuente, Historia del pensamiento político griego. Teoría y praxis (Madrid: Trotta, 2014), 269-271; Ignacio Molina Álvarez de Cienfuegos, Conceptos fundamentales de Ciencia Politica (Madrid: Alianza Editorial, 1998), 128; Lewis Mumford, The Story of Utopias (Nueva York: Boni and Liveright, 1922), 301 y 302. 
propiedad de pequeñas comunidades; (c) propiedad de unidades privadas como la familia; y (d) propiedad individual privada ${ }^{4}$. Esta clasificación ha facilitado que las utopías proyectaran mundos soñados con diferentes regímenes sociopolíticos de propiedad. Para ello partiremos de la siguiente reflexión utópica: si acotar la tierra o circunscribir al individuo lo que antes era de todos produce una profunda injusticia, en sentido contrario colectivizar los bienes y los medios de producción generaría estructuras de convivencia dichosa y por tanto dignas de emulación.

Nuestro propósito consistirá en contraponer la consideración de la propiedad privada en la obra que dio nombre a este género de reflexión literaria, política y social -la Utopía de Moro de la que celebramos su quinto centenario- con otro sueño radicalmente distinto. Nos referimos al distributismo como propuesta de ordenación socioeconómica basada en la extensión de la propiedad privada y de los medios de producción como garantía de la libertad. Una propuesta singularmente representada por el literato Gilbert Keith Chesterton (1874-1936). Confrontamos, por tanto, el pensamiento utópico de dos autores católicos ingleses, pese al contraste entre lo que significaba esta adhesión religiosa en la Inglaterra del s. XVI y la de comienzos del s. XX así como los diferentes entornos sociales.

\section{LA CUESTIÓN DE LA PROPIEDAD EN LA UTOPÍA MOREANA}

Comenzaremos con las observaciones que sobre la propiedad realiza el santo católico Tomás Moro (1478-1535). Conviene recordar que este intelectual y político participará en los acontecimientos que dibujarán una nueva geografía religiosa europea durante el s. XVI, y que en su caso su fidelidad a la sede petrina en Roma le llevó al martirio -junto a otros fieles como el obispo John Fisher- ${ }^{5}$.

Con el pretexto del viaje realizado por el marino Rafael Hythlodaeo, el libro I de su obra Utopía esboza una crítica de los males de su tiempo. Una crítica tal que podría alcanzar la consideración de denuncia de una distopía, la correspondiente a la extensión de un incipiente mercantilismo auspiciado por la burguesía de su momento ${ }^{6}$.

\footnotetext{
${ }^{4}$ Roger Scruton, The Palgrave Macmillan Dictionary of Political Thought (Hampshire: Palgrave Macmillan, 2007), 562-564.

${ }^{5}$ Pese a la proclamación de Enrique VIII como cabeza de la Iglesia, motivada por su infructuosa solicitud de anulación de su matrimonio con Catalina de Aragón, en 1534 merced al Acta de Supremacía, conservaría lo esencial de la fe católica por medio de los Seis artículos de 1539. Tras el restablecimiento del catolicismo por parte de María Tudor (1553-1558), sería Isabel I (1558-1603) la que estableciese definitivamente el anglicanismo en los asuntos espirituales, además de regir en los temporales, dando comienzo a las persecuciones de católicos. Vid. Jean Comby, La historia de la Iglesia (Pamplona: Verbo Divino, 2007), 219 y 200.

${ }^{6}$ Pese al aparente anacronismo que, aparentemente, subyace en el uso de los términos burguesía y proletarización, ambos son utilizados no sólo por su alto valor ilustrativo en el ámbito del sistema de organización económica que promueve la riqueza priva y promueve la competencia y que da inicio en el s. XIII por medio de la concentración de recursos financieros, especialización del trabajo y extensión
} 
Así, este personaje señala que en la base de estos sufrimientos subyace el carácter privado de la propiedad. Ante el trasunto literario del propio Moro, Hythlodaeo aseverará que el aumento de la pobreza sería consecuencia directa de la exclusión de las tierras de labranza. A su vez esto acarreaba la proletarización de los campesinos y el riesgo de comportamientos delictivos. Sus palabras son categóricas:

¡Tan firmemente estoy persuadido de que si no se suprime de raíz la propiedad no se pueden distribuir los bienes según un criterio ecuánime y justo o disponer provechosamente los asuntos de los mortales! Sino que si subsiste, subsistirá para la parte mayor y mejor con mucho de los hombres la ansiosa e ineluctable pesadumbre de la indigencia y de los infortunios7.

Palabras que quizá alcancen su calificación más evidente como origen de los males sociales en las siguientes palabras: «De sanarlos, empero, y de restituirlos a su buena complexión no hay absolutamente ninguna esperanza mientras cada uno posea lo suyo como propio» ${ }^{8}$. Su visita a la isla de Utopía actúa de espejo literario para reflejar un orden ideal ajeno a estos padecimientos. En este sentido, el libro II de Utopía describe la ciudad así como las relaciones entre los utopienses. En su exposición del trazado urbanístico, Hythlodaeo da cuenta de la ausencia de la propiedad privada: "franquean la entrada a quienquiera, a tal punto nada hay nunca privado»" Tampoco existe el dinero ${ }^{10}$. El oro es simple bagatela ornamental sin valor excesivo. Utopía deviene así en elogio de la propiedad colectiva pues nos encontramos en una sociedad liberada del yugo de la acumulación material y de la servidumbre de la propiedad privada. Así lo reconoce Hythlodaeo en sus últimas líneas del libro II:

Aquí, por el contrario, donde todo es de todos, ninguno duda que a nadie le ha de faltar nada privado (con tal que se atienda a que los graneros públicos estén llenos). Pues ni es cicatera la distribución de los bienes ni nadie hay allí indigente o mendigo; no teniendo ninguno nada, son todos, sin embargo, $\operatorname{ricos}^{11}$.

de los mercados. Vid. Molina, Conceptos fundamentales de Ciencia Política, 16 y 17. En este sentido, el término "burguesía" haría alusión a la tradicional división entre aristócratas y sus adversarios, que han obtenido su prestancia social por medio del comercio y el enriquecimiento mercantil. Vid. Scruton, The Palgrave Macmillan Dictionary, 65. Así, aquí el término empleado alude al proceso incipiente de acumulación de la tierra en un número exiguo de manos. Además, el término proletariado, como recuerda Scruton, reaparece en los s. XV y XVI para designar a aquellos que sólo disponen de su fuerza y tiempo de trabajo, no de tierras, que han perdido por deudas o enajenaciones. Vid. Ibídem, 561. Por tanto, no se aludirá al proletariado en un sentido marxista. Burguesía y proletariado servirán como herramientas para evidenciar el lúcido análisis que la Utopía moreana realizará de la Europa de su momento, especialmente en su libro primero. Cfr. Rafael Herrera Guillén, Breve bistoria de la utopia (Madrid: Nowtilus, 2013), 96 y 97.

7 Tomás Moro, Utopía (Madrid: Tecnos, 2006), 43.

8 Ibídem, 44.

${ }^{9}$ Ibídem, 54.

${ }^{10}$ Ibídem, 73.

11 Ibídem, 128. 
En definitiva, la propiedad privada queda señalada como origen de toda desigualdad.

\section{EL DISTRIBUTISMO CHESTERTONIANO Y LA EXTENSIÓN DE LA PROPIEDAD PRIVADA}

En contraposición con este análisis, otro eximio católico -Gilbert Keith Chesterton- nos ofrece su propia solución utópica. Nos llama la atención el carácter radicalmente distinto de la solución frente al colectivismo moreano. En el distributismo, la extensión y generalización de la propiedad privada sería el remedio al problema de la desigualdad social. Señalaremos que el pensamiento político de este autor ha sido convencionalmente adscrito al conservadurismo. Conviene recordar, en este sentido, que el orden industrial resultó ajeno, en un primer momento, a los valores conservadores. Los cambios profundos de la industrialización quebraban el quietismo del mundo agrícola y rural que vertebraba la filosofía conservadora. El conservadurismo, además, consideraba que la economía no era una estructura prepolítica y que el liberalismo situaba el eje de su teoría económica en el individualismo disgregador si bien los conservadores terminarían por aceptar especialmente durante la época de Chesterton- la visión liberal del mercado y el laissezfaire para contrarrestar el socialismo. En consecuencia, atenderemos en primer lugar al contexto y consecuencias del distributismo (2.1.) para, posteriormente, abordar su manifestación en la obra de Chesterton.

\section{Contexto histórico del distributismo y vínculos con la Doctrina Social de la Iglesia}

Si atendemos a esta tesis, la propiedad privada forma parte del vocabulario con el que un conservador se relaciona con su entorno. Así, para Chesterton la propiedad privada es fuente de lealtades, adhesiones a la comunidad y derecho prepolítico antes que absolutización de un derecho moral o elemento de adquisición competitiva ${ }^{12}$. En este sentido, Chesterton fue junto a Hilaire Belloc uno de los fundadores del distributismo, o lo que es lo mismo, una tercera vía entre el colectivismo socialista y el capitalismo individualista ${ }^{13}$. Con esta concepción de la propiedad privada como

\footnotetext{
${ }^{12}$ John Hoffman y Paul Graham, Introduction to Political Concepts (Harlow: Pearson, 2006), 189; Roger Scruton, Conservative Texts. An Anthology (Hampshire: MacMillan, 1991), 23.

${ }^{13}$ Esta tercera vía subsanaría, a juicio de sus defensores, las injusticias tanto del capitalismo como del socialismo. Vid. Jay P. Corrin. "The Chesterbelloc and Modern Sociopolitical Criticism", en G. K. Chesterton and C. S. Lewis: The Riddle of Joy, ed. M. J. MacDonald y A. Tadie (Michigan: Wm. B. Eerdmans, 1989), 173 y 174. Además, vaticinaría planteamientos propios de la futura democracia cristiana posterior a la II Guerra Mundial. Por parte de Hilaire Belloc, uno de los hitos del distributismo será la publicación del libro El Estado servil (1912). Belloc persigue «probar la verdad siguiente: Que nuestra sociedad moderna, en la cual sólo unos pocos poseen los medios de producción, hallándose necesariamente en
} 
fundamento prepolítico, el distributismo postularía la justa extensión de la pequeña propiedad privada ${ }^{14}$. También abogaría por la necesaria difusión de las sociedades intermedias. La lógica de esta propuesta resultaba nítida: frente a la degradación antropológica del individualismo atomizador y competitivo liberal era preciso extender la propiedad y recuperar el gremialismo ${ }^{15}$. Por otra parte, sólo así quedaba garantizada la libertad individual y se ponía coto a la concentración del poder estatal del colectivismo.

Para comprender mejor la impugnación capitalista que formularía Chesterton, considero pertinente recuperar los textos del Magisterio eclesiástico que conformarían los pilares de la Doctrina Social de la Iglesia, que inspirarían a los distributistas y que,

equilibrio inestable, tiende a alcanzar una condición de equilibrio estable mediante la implantación del trabajo obligatorio, legalmente exigible a los que no poseen los medios de producción, para beneficio de los que los poseen» (Hilaire Belloc, El Estado servil, Madrid: El buey mudo, 2007), edición Kindle, pos. 291-299. Su propuesta de una alternativa, por exclusión de las restantes, anticipa el distributismo: "Presentaré luego las tres únicas soluciones posibles: a) El colectivismo, que pone los medios de producción en manos de los agentes políticos de la comunidad. b) La propiedad, o restablecimiento de un Estado Distributivo, en que todos los ciudadanos poseen individualmente los medios de producción. c) La esclavitud, o un Estado Servil, en el cual los que no posean los medios de producción se verán compelidos legalmente a trabajar para aquellos que los poseen, y tendrán asegurada, a cambio, la subsistencia... Es fácil demostrar que esta segunda solución atrae de la forma más natural y sencilla a una sociedad ya capitalista" (Ibídem, pos. 313-318).

14 Realmente no fueron los únicos en defender esta tercera vía de la pequeña propiedad. Su origen puede situarse en los intentos de aplicar la encíclica Rerum novarum (1891): «Sus antecedentes inmediatos pueden trazarse fácilmente en la preocupación social del cristianismo en la Inglaterra del siglo XIX» (Salvador Antuñano Alea, "El distributismo inglés: una alternativa de raíz tomista a los totalitarismos del siglo XX", Cuadernos de Pensamiento 16, 2004: 280). Para Daniel Sada, que realizó su tesis doctoral sobre el distributismo inglés en el primer tercio del siglo XX, Chesterton fue la autoridad moral de la Liga Distributista, fundada gracias al llamamiento realizado desde el periódico G. K.'s Weekly. -dirigido por el propio Chesterton desde 1925 hasta su muerte en 1936-. Vid. Daniel Sada Castaño, Gilbert Keith Chesterton y el distributismo inglés en el primer tercio del siglo XX (Madrid: Fundación Universitaria Española, 2005). Antuñano apunta también a la influencia distributista en J. R. R. Tolkien: «El modelo de sociedad rural según el ideal del Distributismo puede verse reflejado en la vida de "La comarca" de los hobbits de la Tierra Media de Tolkien: se trata de "una era pre-mecánica", pre-industrial, libre, comunitaria, solidaria. De acuerdo con este ideal se quiere revitalizar la sociedad rural, como camino de libertad personal〈@〉 (Antuñano, "El distributismo inglés", 289).

15 "Los distributistas, tenían dos propósitos en mente cuando defendían la propiedad como garante de la libertad. Primero, veían la propiedad como fuente real y práctica de poder individual, necesario para institucionalizar la libertad real. Segundo, veían la propiedad como la culminación de las necesidades espirituales del hombre y la expresión de su libertad" (Sada, Gilbert Keith Chesterton, 250 y 251). En su impugnación del capitalismo, y su inevitable consecuencia -la aparición de una plutocracia-, Chesterton "reconoció los primeros signos de una agresión antropológica sin precedentes mediante la cual el 'materialismo abstracto' de los ricos estaba a punto de dejar a una gran parte de la humanidad sin el refugio de una sociedad en la que poder seguir reproduciendo, como al bies o entre líneas, inalcanzables para los predicadores, los lazos más básicos de la supervivencia", Alba Rico, "Prólogo: Defensa del sedentarismo andante" en G. K. Chesterton, La taberna errante (Madrid: Acuarela-Antonio Machado, 2004), 19 y 20. 
finalmente, serían recogidos por la democracia cristiana ${ }^{16}$. A finales del siglo XIX, la cuestión obrera o social fue objeto de las reflexiones no sólo de ideologías y partidos políticos. La Iglesia católica, por su parte, dedicó su atención, especialmente al capitalismo, el liberalismo económico, la propiedad privada y el destino privado de los bienes. Así lo refleja la encíclica Rerum novarum sobre la situación de los obreros (1891), que influirá profundamente en católicos como Chesterton o Belloc ${ }^{17}$. Ambos también vertebrarían propuestas prácticas para articular la encíclica Quadragesimo anno, que celebraría en 1931 las cuatro décadas desde la aparición de Rerum novarum. Estas encíclicas fueron, por otra parte, referentes en la vertebración de la democracia cristiana, compatible con el conservadurismo anglosajón. Atenderemos a estas cuestiones desde dos ámbitos separados, por una parte, el capitalismo (a) y por otra parte la propiedad privada (b).

Respecto del orden capitalista y del liberalismo económico (a), su impugnación fue una constante de los documentos de la Doctrina Social de la Iglesia, sólo eclipsada por el repudio de la alternativa colectivista del marxismo, hasta la II Guerra Mundial. A partir de los años 50 se optó por "una postura más benévola, coincidiendo con la transformación que supone el abandono del capitalismo liberal (de mercado puro) y el paso al capitalismo mixto. La combinación de iniciativa privada e intervención pública parece una fórmula capaz de conjugar crecimiento económico y justicia" ${ }^{18}$. La encíclica

${ }^{16} \mathrm{El}$ ambiente católico inglés de finales del s. XIX y comienzos del XX resulta obviamente distinto al que conoció Moro, con carácter previo a la ruptura del monarca con Roma. En el primer caso, aludimos a un catolicismo que opera en un ambiente de secularización creciente y que recurre a un metalenguaje contextual, ajeno a cualquier narrativa metafísica y trascendente, todo ello en mitad de un ambiente de industrialización y conflictividad social por la denominada cuestión obrera. Es posible hablar de un renacimiento católico en Inglaterra, tanto por el número de fieles como por la personalidad de sus responsables -que alcanzarían relevancia teológica, social y política-. Vid. Comby, La historia de la Iglesia, 323. Por ejemplo, es posible aludir a los cardenales Newman y Manning, el presbítero Robert Hugh Benson, los literatos y políticos Belloc, Baring y el propio Chesterton, los académicos Tolkien, Dawson y Elliot. Cfr. Joseph Pearce, Escritores conversos. La inspiración espiritual en una época de incredulidad (Madrid: Palabra, 2009).

17 Podemos atender al editorial del G. K.'s Weekly de 23 de mayo de 1931, con motivo de los cuarenta años de la encíclica Rerum novarum con el título de "Forty Years On" que escribió el propio Chesterton: «This Encyclical, in its few but brilliant pages of wisdom and exhortation, presents so clear an outline of that social philosophy we call Distributism, and for the furtherance of which this paper exists, that no excuse is necessary to Distributists of any creed for reminding them of a book so bound up with their aims an so characterised by humanity and vision. The present Pope, Pius XI, deserves the gratitude of Distributists, as indeed of the whole world, for deliberately advancing the jubilee of Rerum novarum by ten years in order to draw attention to its supreme applicability in present social and industrial conditions», G. K. Chesterton (ed.), Gks Weekly. A Sampler (Chicago: Loyola University Press, 1986), 303. La influencia de la encíclica en el distributismo parece fuera de toda controversia.

${ }^{18}$ Ildefonso Camacho, Doctrina social de la Iglesia. Quince claves para su comprensión (Bilbao: Desclée de Brouwer, 2000), 43. Camacho puntualiza esta tendencia motivada por la consolidación en Europa Occidental de lo que se dio en llamar Estado de bienestar. Este modelo mixto que combinaba libertad económica con intervención distributiva estatal mereció el elogio de la Doctrina Social de la Iglesia. Así se puede comprobar en Mater et Magistra (1961), de San Juan XXIII, que rebajó el tono polémico al tiempo que optaba preferencialmente por la economía de modelo mixto, con prioridad a la iniciativa 
Rerum novarum del sumo pontífice León XIII sobre la situación de los obreros (1891) señalaba que las causas de la miseria de las clases trabajadoras son la supresión de los gremios y el afán de lucro -la usura- ${ }^{19}$ y se condenaba la solución socialista a la cuestión obrera ${ }^{20}$. No obstante, también critica la violencia del capitalismo liberal y llama a su clausura por medio de la concurrencia de Iglesia, Estado y tanto patronos como obreros. Cuatro décadas después, la encíclica Quadragesimo anno aseveró con rotundidad que la libre competencia habría dado lugar a una concentración de poder que se manifiesta en forma de dictadura económica ${ }^{21}$. Esta encíclica destacó la función subsidiaria del Estado y frente a la tensión contrato social liberal/lucha de clases $^{22}$, estableció un

privada (numeral 51) pero corregida desde el poder estatal (numerales 52, 56 y 57). Populorum progressio (1967), del beato Pablo VI, criticaría los excesos del capitalismo - v.gr. hacer del lucro el único motor de la economía y de la competitividad un valor social fundamental- (numerales 25 y 26). No obstante, en Octogesima adveniens (1971), del mismo autor, se defiende la apología liberal de los valores de iniciativa personal y defensa del individuo frente al totalitarismo al tiempo que se impugnan sus deficiencias primacía de la eficiencia económica y sustento metafísico erróneo de una falsa autonomía individual(numeral 35). Posteriormente, San Juan Pablo II «distingue la economía de mercado, que le merece un juicio favorable, y la concepción de la libertad que le inspira, frente a la que se muestra mucho más crítico. Pero en esta distinción estamos de nuevo afrontados a la interrelación entre capitalismo (como mero sistema de organización económica) y liberalismo (como ideología inspiradora y legitimadora); y no hay duda que es en esta ideología, y no en el sistema, donde Juan Pablo II concentra todas sus profundas reservas» (Camacho, Doctrina social de la Iglesia, 44). En este sentido, en Sollicitudo rei socialis (1987), de San Juan Pablo II, se subraya el valor del derecho a la iniciativa económica como subjetividad creativa del ciudadano (numeral 15). Del mismo pontífice, Centesimus annus (1991) celebró el centenario de Rerum novarum. Postula que el mercado tiene limitaciones, que obligan a hetero-correcciones estatales (numerales 34 y 40). Censura el reduccionismo de la persona a la categoría de consumidor (39) y trata de responder a la pregunta sobre si es aceptable el capitalismo. Lo sería como sistema económico pero no como fundamentación antropológica de la libertad absoluta en lo económico (numeral 42).

19 «(1)... Sea de ello, sin embargo, lo que quiera, vemos claramente, cosa en que todos convienen, que es urgente proveer de la manera oportuna al bien de las gentes de condición humilde, pues es mayoría la que se debate indecorosamente en una situación miserable y calamitosa, ya que, disueltos en el pasado siglo los antiguos gremios de artesanos, sin ningún apoyo que viniera a llenar su vacío, desentendiéndose las instituciones públicas y las leyes de la religión de nuestros antepasados, el tiempo fue insensiblemente entregando a los obreros, aislados e indefensos, a la inhumanidad de los empresarios y a la desenfrenada codicia de los competidores. Hizo aumentar el mal la voraz usura, que, reiteradamente condenada por la autoridad de la Iglesia, es practicada, no obstante, por hombres codiciosos y avaros bajo una apariencia distinta. Añádase a esto que no sólo la contratación del trabajo, sino también las relaciones comerciales de toda índole, se hallan sometidas al poder de unos pocos, hasta el punto de que un número sumamente reducido de opulentos y adinerados ha impuesto poco menos que el yugo de la esclavitud a una muchedumbre infinita de proletarios» (Rerum novarum).

${ }^{20}$ Lo haría en un doble plano: al oponerse al fin lícito del trabajo que persigue obtener un salario y al contradecir las dimensiones personal, familiar y social del ser humano.

21 «(105) Salta a los ojos de todos, en primer lugar, que en nuestros tiempos no sólo se acumulan riquezas, sino que también se acumula una descomunal y tiránica potencia económica en manos de unos pocos, que la mayor parte de las veces no son dueños, sino sólo custodios y administradores de una riqueza en depósito, que ellos manejan a su voluntad y arbitrio» (Quadragesimo anno).

22 «(107) Esta acumulación de poder y de recursos, nota casi característica de la economía contemporánea, es el fruto natural de la limitada libertad de los competidores, de la que han sobrevivido sólo los más poderosos, lo que con frecuencia es tanto como decir los más violentos y los más desprovistos de conciencia» (Quadragesimo anno). 
principio rector económico que descansaba en la justicia y la caridad ${ }^{23}$. En segundo lugar (b), la propiedad será afirmada de acuerdo a la estructura teológica de señorío del hombre en relación con el uso de los bienes ${ }^{24}$. Rerum novarum defiende el derecho a la propiedad privada, con un principal argumento a favor: la naturaleza humana ${ }^{25}$. Tal defensa del orden constituido frente a las revoluciones socialistas no implica que la Iglesia aceptase el fundamento individualista, competitivo e inmanente de la propiedad que formuló el liberalismo económico pues si esta encíclica "es abiertamente antisocialista, no puede deducirse de ahí que sea proliberal" ${ }^{26}$. También presenta otros dos argumentos a favor de la propiedad: el derecho a apropiarse del fruto de su trabajo y la vinculación que genera con la patria ${ }^{27}$. Esto no implica que exista contradicción entre el derecho a la propiedad privada y el destino universal de los bienes, pues es fuente de obligaciones morales que limitan una libertad irrestricta ${ }^{28}$. Finalmente, todos deben tener acceso a la propiedad privada y los obreros deben contar con un salario que permita el ahorro. En este empeño, el Estado tiene un papel fundamental. Por su

23 «(109)... A esto se añaden los daños gravísimos que han surgido de la deplorable mezcla y confusión entre las atribuciones y cargas del Estado y las de la economía, entre los cuales daños, uno de los más graves, se halla una cierta caída del prestigio del Estado, que, libre de todo interés de partes y atento exclusivamente al bien común a la justicia debería ocupar el elevado puesto de rector y supremo árbitro de las cosas; se hace, por el contrario, esclavo, entregado y vendido a la pasión y a las ambiciones humanas» (Quadragesimo anno).

24 «Tres etapas podrían distinguirse en esta evolución. La primera va matizando y corrigiendo el derecho de propiedad con la función social de la propiedad: ya lo hizo, aunque tímidamente, León XIII; lo harán más decididamente Pío XI y Pío XII. La segunda afirma ya sin ambages la propiedad del destino universal de los bienes, que es la única razón que justifica la propiedad privada así como el criterio para legitimarla en cada caso... En la tercera etapa, Juan Pablo II subraya con fuerza (Laborem exercens) la subordinación de los bienes materiales (el capital productivo) al trabajo humano, hasta llegar a admitir que dicha función lo mismo puede ser realizada por la propiedad privada que por la pública: porque lo decisivo es que, sea cual sea el sistema de propiedad, ésta esté al servicio de la persona humana» (Camacho, Doctrina social de la Iglesia, 74).

25 «(4)... Lo que se acusa y sobresale en nosotros, lo que da al hombre el que lo sea y se distinga de las bestias, es la razón o inteligencia. Y por esta causa de que es el único animal dotado de razón, es de necesidad conceder al hombre no sólo el uso de los bienes, cosa común a todos los animales, sino también el poseerlos con derecho estable y permanente, y tanto los bienes que se consumen con el uso cuanto los que, pese al uso que se hace de ellos, perduran» (Rerum novarum).

${ }^{26}$ Camacho, Doctrina social de la Iglesia, 73 . «(11)... cuando se plantea el problema de mejorar la condición de las clases inferiores, se ha de tener como fundamental el principio de que la propiedad privada ha de conservarse inviolable» (Rerum novarum).

${ }^{27}$ «(7) ... cuando el hombre aplica su habilidad intelectual y sus fuerzas corporales a procurarse los bienes de la naturaleza, por este mismo hecho se adjudica a sí aquella parte de la naturaleza corpórea que él mismo cultivó, en la que su persona dejó impresa una a modo de huella, de modo que sea absolutamente justo que use de esa parte como suya» (Rerum novarum).

$28 \ll(6) \ldots$ El que Dios haya dado la tierra para usufructuarla y disfrutarla a la totalidad del género humano no puede oponerse en modo alguno a la propiedad privada. Pues se dice que Dios dio la tierra en común al género humano no porque quisiera que su posesión fuera indivisa para todos, sino porque no asignó a nadie la parte que habría de poseer, dejando la delimitación de las posesiones privadas a la industria de los individuos y a las instituciones de los pueblos» (Rerum novarum) «... (17) A nadie se manda socorrer a los demás con lo necesario para sus usos personales o de los suyos; ni siquiera a dar a otro lo que él mismo necesita para conservar lo que convenga a la persona, a su decoro» (Rerum novarum). 
parte, la encíclica Quadragesimo anno recordó el necesario equilibrio entre la dimensión individual y social de la propiedad privada ${ }^{29}$. Pese a ello, el uso incorrecto de este derecho no justificaría su desaparición.

El distributismo, entonces, surge como una versión anglosajona del catolicismo social y político, inspirado también por el guildismo -como corriente de organización socioeconómica democráticamente postindustrial fundada en la organización de corporaciones o gremios medievales $-{ }^{30}$ y caracterizado por los siguientes rasgos: subsidiariedad, solidaridad y cooperación ${ }^{31}$. Unos rasgos que, décadas después, subyacerán en las propuestas políticas emanadas del catolicismo, como por ejemplo en la democracia cristiana de la posguerra en Europa ${ }^{32}$.

\section{Chesterton y su producción intelectual distributista}

La impugnación chestertoniana del capitalismo aparece en su obra La utopía capitalista y otros ensayos (1917) ${ }^{33}$, en diversos artículos del periódico G. K.'s Weekly y en su novela El regreso de Don Quijote. En la primera obra defendería el derecho natural a la propiedad privada frente a sus posibles abusos: "la propiedad privada, como tal, no es lo mismo que propiedad limitada a unos pocos"34. Vindicación que presentará por medio del protagonista de la novela El regreso de Don Quijote: "la ley antigua reconocía

${ }^{29}$ «(47)...La justicia llamada conmutativa manda, es verdad, respetar santamente la división de la propiedad y no invadir el derecho ajeno excediendo los límites del propio dominio; pero que los dueños no hagan uso de los propio si no es honestamente, esto no atañe ya dicha justicia, sino a otras virtudes, el cumplimiento de las cuales "no hay derecho de exigirlo por la ley"» (Quadragesimo anno).

30 Sergio Fernández Riquelme, "«Tres acres y una vaca». El distribuismo o la radical opción moral de la economía contemporánea", Veritas 26 (2012): 167-170. http://dx.doi.org/10.4067/S071892732012000100008 [consultado el 4 de noviembre de 2017].

${ }^{31}$ Fernández Riquelme, “Tres acres y una vaca”, 172.

${ }^{32}$ La democracia cristiana es una ideología de inspiración católica, con origen en el intento de la Iglesia católica a finales del siglo XIX de combatir el socialismo y el liberalismo. Vertebraría un movimiento político popular interclasista, con una fuerte base trabajadora, lo que le diferenciará de la derecha conservadora tradicional. Se configuró a través de las encíclicas de la Doctrina Social de la Iglesia y de las elaboraciones teóricas de pensadores como Leclerq, Messner, Maritain o Mounier. En sus diversas plasmaciones geográficas defenderá principios ideológicos comunes como los siguientes: personalismo, familismo, comunitarismo, subsidiariedad, pluralismo y solidarismo -concertación de intereses en la sociedad por solidaridad- así como el centrismo. Todos ellos desembocarán en una teoría personalista, lo que le permitirá compartir con el liberalismo su defensa del individuo y los derechos humanos, pero no la visión antropocéntrica y secular de aquél, al tiempo que compartiría con el socialismo la asunción de los derechos colectivos, pero sin concretar en el Estado el papel de clausurar el conflicto social. De ahí su comunitarismo en el ejercicio de la responsabilidad de construir una comunidad social. Vid. Molina, Conceptos fundamentales de Ciencia Política, 36 y 37; Cesáreo R. Aguilera de Prat. "Democracia cristiana: ¿existe un pensamiento político democristiano?", en Ideologías y movimientos politicos contemporáneos, ed. Joan Antón (Madrid: Tecnos, 1998), 275-284.

${ }^{33}$ Elocuentemente titulada Utopia of Usurers and Other Essays en su edición original.

34 Gilbert Keith Chesterton, La utopia capitalista y otros ensayos (Madrid: Palabra, 2013), 63; en su edición original, Utopia of Usurers and Other Essays, Collected Works, vol. V (San Francisco: Ignatius Press, 1987), 435. 
igualmente otros derechos: el de la propiedad privada... la ética y la jurisprudencia medievales consagraban el principio de la propiedad privada, de manera más elaborada que la mayoría de los sistemas modernos" 35 . La apología de este derecho natural a la propiedad privada recogía las orientaciones de la Encíclica Rerum novarum del Papa León XIII sobre la situación de los obreros (1891). Esta Encíclica condenaba también la supresión de los gremios y el afán de lucro -la usura- como causas de la miseria de las clases trabajadoras al tiempo que censuraba la solución socialista. El derecho a la propiedad privada contaba con tres argumentos favorables: "El derecho de poseer bienes en privado no ha sido dado por la ley, sino por la naturaleza" 36 , el derecho a apropiarse del fruto de su trabajo y los lazos de lealtad que suscita. Su uso injusto, como señalaba Chesterton, no puede justificar nunca su desaparición. Por tanto, tampoco existe contradicción entre su existencia y el destino universal de los bienes ${ }^{37}$.

El distributismo chestertoniano vertebraría utópicamente la extensión de la propiedad privada. Para ello presentaría ante nosotros la Feliz Inglaterra, donde todos poseen la tierra en la que viven y trabajan, como una formulación nítidamente retrotópica ${ }^{38}$. Así, frente a las utopías futuristas y futuribles de modelos de sociedades difícilmente realizables, en el pensamiento de Chesterton encontramos la impugnación retrotópica al vínculo utópico con el posible futuro por medio de un juicio crítico del presente, de un ideal realizable y de promesas teleológicas de futuro -especialmente desde la Ilustración y las subsecuentes revoluciones francesa, industrial y científica la utopía miraría temporalmente al futuro- ${ }^{39}$.

35 Gilbert Keith Chesterton, El regreso de don Quijote (Madrid: Valdemar, 2005), 348 y 349; en su edición original, The Return of Don Quixote, Collected Works, vol. VIII (San Francisco: Ignatius Press, 1999), 227 y 228.

36 Rerum novarum, $\mathrm{n}^{\mathrm{o}} 33$.

${ }^{37}$ Rerum novarum, $\mathrm{n}^{\circ} 6$.

${ }^{38}$ Frente a las utopías consideradas proyecciones futuribles de un modelo de sociedad difícilmente realizable, el no-lugar también puede ser retrotópico, como un mundo ideal ubicado en un pasado perdido, robado o abandonado que se resiste a morir ante un futuro aún por nacer. Vid. Zygmunt Bauman, Retrotopía (Barcelona: Paidós, 2017), Ed. Kindle, 90-118.

${ }^{39}$ En este sentido, los estudios utópicos, con su profunda polisemia, tampoco permanecen ajenos a las servidumbres del tiempo. Cfr. Molina, Conceptos fundamentales de Ciencia Política, 128; John Gray, Anatomía de Gray (Barcelona: Paidós, 2011), 231. De anunciar el no-lugar pasó a vislumbrar el no-tiempo; de la utopía a la ucronía y de ahí, normativamente, hasta postular el mejor tiempo -la eucronía-. El camino de la utopía abandonó el mapa y el territorio para buscar el horizonte de Cronos. El auge de las utopías tecnocientíficas y progresistas resulta evidente en la obra del socialista fabiano H. G. Wells. Vid. Krishan Kumar, Utopianism (Buckingham: Open University Press, 1991), 2 y 3; Barbara Goodwin y Keith Taylor, The Politics of Utopia. A Study in Theory and Practice (Oxford: Peter Lang, 2009), 11-18; Amable Fernández Sanz, "Utopía, progreso y revolución como categorías explicativas en la historia del pensamiento", Anales del Seminario de Historia de la Filosofía 12 (1995), 169-171; y Javier Nicolás González Camargo, "Topía y cronía de lo utópico y lo ucrónico - Recuentos y valoraciones entre la literatura y la filosofía", Prometeica-Revista de Filosofía y Ciencias 2 (2010), 7 y 16-19. Para atender al posible carácter ucrónico tradicionalista o a la transversalidad humanista en el catolicismo político del distributismo chestertoniano, vid. Fernández Riquelme, “Tres acres y una vaca”, 184. 
Simultáneamente a esta coordenada temporal, la utopía distributista defendía la organización cooperativa de los trabajadores y el fortalecimiento de las instituciones intermedias. Los gremios medievales eran el ejemplo más vívido de esta propuesta. En este sentido, una economía respetuosa con la dimensión antropológica precisaba de comunidades orgánicas, solidarias y autosuficientes. Esta defensa de las instituciones intermedias, como hemos visto, mantiene una afinidad sustancial con la Doctrina Social de la Iglesia. Distributismo y catolicismo político, a la vista de lo expuesto en la doctrina Rerum novarum, quedan así indudablemente unidas ${ }^{40}$. A mayor abundamiento, el distributismo partía de una concepción realista del hombre -apela a su libertad pese a la antropología de la imperfección y del inevitable pesar-. Por tanto, no anhelaba un futuro irrealizable. Al mirar a un pasado que se proyectaba hacia lo eterno, el distributismo no soñaba un futuro libre de la carga del sufrimiento ni proponía un anhelo nostálgico ${ }^{41}$. Destacamos, en este sentido, el carácter novedoso de esta utopía que pretende restituir por medio de la propiedad la libertad usurpada por el nuevo orden industrial. Como defiende Vega Rodríguez, "lo que los distributistas defienden es justamente lo contrario de lo que han propuesto todas las utopías para alcanzar la concordia social, incluso desde Moro" ${ }^{42}$. Su objetivo resultaba más modesto, pues únicamente ejemplificaba un cuadro sociopolítico dulcificado económicamente y digno de emulación. En este sentido, encontramos también el contraste entre el entorno social del s. XVI, sujeto y objeto del diálogo intelectual de Moro con su época, y el que conoce Chesterton, a finales del s. XIX y principios del XX. Por esta razón, frente a las utopías agrarias y rurales coetáneas de la Utopía moreana, evidenciadas por la Ciudad del Sol de Campanella o las arcadias agrarias posteriores, que alcanzarían incluso a los socialistas utópicos, durante el s. XIX la revolución industrial confrontará el modelo campestre de lo utópico con el urbano ${ }^{43}$.

La defensa de esta utopía de la propiedad privada la encontramos en la novela El regreso de Don Quijote. Como aseverará en sus páginas el líder sindicalista Braintree: “-para nosotros, las minas deben pasar a ser propiedad de los mineros... A mí no me

${ }^{40}$ Joseph Pearce, G. K. Chesterton. Sabiduría e inocencia (Madrid: Encuentro, 2011).

${ }^{41}$ Sada Castaño, Gilbert Keith Chesterton, 202, 257 y 258.

42 Pilar Vega Rodríguez, "Chesterton y Maeztu ante la utopía quijotesca”, Espéculo. Revista de Estudios Literarios 38 (2008). https://pendientedemigracion.ucm.es/info/especulo/numero38/chesmaez.html [consultado el 29 de abril de 2016].

43 Simultáneamente, durante el s. XIX se producirá un importante resurgimiento de la literatura utópica con publicaciones que abarcan desde el socialismo a la ciencia ficción, los viajes extraordinarios a Australia y Nueva Zelanda. Cfr. Lyman Tower Sargent. "Utopian Traditions: Themes and Variations", en Utopia. The search for the ideal Society in the western world, ed. Gregory Claeys y Lyman Tower Sargent (Nueva York: Oxford University Press, 2000), 13. No resultaría casual el auge de las utopías científicas, herederas de la ciencia, la tecnología y la idea de progreso indefinido -como el Viaje a Icaria de Étienne Cabet-. Un buen ejemplo lo tenemos en H. G. Wells, con sus anticipaciones del futuro que incluían elementos de las ciencias sociales y la filosofía para dar respuesta a sus inquietudes como socialista fabiano, que décadas más tarde tendría su réplica en G. K. Chesterton y C. S. Lewis (Krishan Kumar, Utopia \& Anti-utopia in Modern Times (Oxford: Basil Blackwell, 1991), 28-31 y 387. También surgirán utopías agrarias e historicistas, como la propugnada por William Morris, Noticias de ninguna parte. 
parece - dijo- que alguien haya advertido hasta ahora que sea una utopía propia de salvajes que la flauta pertenezca al flautista" ${ }^{44}$. El propio iniciador de la charada que vertebrará el argumento de esta obra, el bibliotecario Michael Herne, "se convierte en el abanderado del distributismo" en su discurso final sobre la Edad Dorada y la necesidad de devolver los títulos de propiedad a sus legítimos dueños ${ }^{45}$. Así, evitar la aparición de la plutocracia, en línea con lo expuesto en la encíclica Rerum novarum, motivará el desarrollo de esta novedosa utopía de pequeños propietarios, de medios de producción compartidos por sus trabajadores y de gremios comunales. Creemos que existen fundamentos suficientes para clasificar este modelo económico como una utopía igualitaria, nostálgica del pasado, democrática, pesimista respecto a la naturaleza humana - pues surge para evitar la competencia por recursos escasos- y estaría encaminada a satisfacer necesidades materiales.

De este modo, si atendemos a las categorías de la utopía que nos proporcionan Manuel y Manuel, nos encontraríamos ante una utopía suave, estática, espiritual, plebeya, de realización e individualista ${ }^{46}$. En el caso de aplicar los criterios de Krishan Kumar encontraríamos una curiosa paradoja: Chesterton hará suyos el criterio del estatismo, propio del mundo antiguo, junto con otros propios del utopismo moderno como el igualitarismo y la garantía de la prosperidad material ${ }^{47}$. También destacamos su carácter de utopía agraria y ascética ${ }^{48}$. Finalmente, si seguimos las categorías de Sargent, el distributismo chestertoniano sería verdadera eutopía, el buen lugar, el mundo posible y deseable frente a aquel en el que habitamos ${ }^{49}$. Nos encontramos ante una aproximación novedosa al pensamiento utópico. En su propuesta de sentido resonará una intuición: el equitativo reparto de la propiedad y la recuperación del sindicalismo ajeno a la lucha de clases permitirían superar los reduccionismos antropológicos del capitalismo competitivo y del colectivismo comunista. Esta narrativa medievalizante y gremialista era susceptible de emulación y no implicaba ninguna ruptura con el hilo transhistórico del principio de tradición ni con la antropología prelapsaria y amartiocéntrica.

\section{CONCLUSIONES}

En síntesis, hemos querido acreditar el carácter destacado de la propiedad en las propuestas utópicas. Destacamos que se trata de uno de los elementos sobre los que ha pivotado la reflexión acerca de la desigualdad. En nuestro planteamiento hemos

\footnotetext{
44 Chesterton, El regreso de don Quijote, 30 y 31.

45 Vega Rodríguez, "El regreso de don Quijote de Chesterton. Tradición y utopía", Anales Cervantinos, 37 (2005), 245.

46 Manuel y Manuel, Utopian Thought, 12.

${ }^{47}$ Kumar, Utopia \& Anti-utopia, 32.

${ }^{48}$ George Kateb, Utopia and Its enemies (Nueva York: Schocken 1972), 5.

${ }^{49}$ Lyman Tower Sargent, "The Three Faces of Utopianism Revisited", Utopian Studies 5-1 (1994), 11 y 12 .
} 
recurrido a una confrontación de dos modelos de un orden social deseable. El primero, la célebre Utopía moreana, aborda esta cuestión por medio de la apología de la propiedad colectiva y la supresión de la privada. La segunda propuesta, contenida en el distributismo chestertoniano, asevera que la extensión de la propiedad privada -y de las instituciones intermedias - no sólo evita las desigualdades. Se constituye también en garantía de la libertad individual. Con independencia del posible grado de realización de ambas propuestas, su influencia fue evidente. Canonizado y declarado patrón de los políticos el canciller Moro e intérprete cualificado de la Doctrina Social de la Iglesia el literato Chesterton, sus respuestas también alcanzaban un punto de acuerdo. A saber, que el progreso no supone marchamo necesario para paliar la desigualdad. Al contrario, la retirada de la lógica competitiva y la necesidad de recuperar el primigenio vínculo con la tierra suponían la mejor receta frente a la desigualdad. En su centro, siempre aparece la propiedad, ya sea colectiva o privada, para tratar de trazar el retrato de esa sociedad que no es la nuestra pero que actuaría como factoría de la felicidad. Ese retrato pasaría por dos alternativas: propiedad para nadie, nos dice la Utopía moreana, o todos propietarios, defiende el distributismo chestertoniano.

\section{BIBLIOGRAFÍA}

Aguilera de Prat, C. R., "Democracia cristiana: ¿existe un pensamiento político democristiano?" en Antón, K. (ed.), Ideologías y movimientos políticos contemporáneos (Madrid: Tecnos, 1998), 275-299.

Alba Rico, "Prólogo: Defensa del sedentarismo andante" en Chesterton, G. K., La taberna errante (Madrid: Ediciones Acuarela y Antonio Machado Libros, 2004), 7-24.

Antuñano, Salvador, "El distributismo inglés: una alternativa de raíz tomista a los totalitarismos del siglo XX", Cuadernos de Pensamiento 16, 2004, 277-300.

Barceló, Pedro y David Hernández de la Fuente, Historia del pensamiento político griego. Teoría y praxis (Madrid: Editorial Trotta, 2014).

Bauman, Zygmunt, Retrotopía (Barcelona: Paidós, 2017), Ed. Kindle.

Belloc, Hilaire, El Estado servil, El buey mudo, Madrid, 2007, edición Kindle.

Camacho, I., Doctrina social de la Iglesia. Quince claves para su comprensión (Bilbao: Desclée de Brouwer, 2000). 
Chesterton, Gilbert Keith, El regreso de don Quijote (Madrid: Valdemar, 2005).

Chesterton, Gilbert Keith, La utopia capitalista y otros ensayos (Madrid: Biblioteca Palabra, 2013).

Chesterton, G. K. (ed.), Gks Weekly. A Sampler (Chicago: Loyola University Press, 1986).

Comby, Jean, La historia de la Iglesia (Pamplona: Editorial Verbo Divino, 2007).

Corrin, Jay P., "The Chesterbelloc and Modern Sociopolitical Criticism" en MacDonald, M. J. y Tadie, A. (eds.), G. K. Chesterton and C. S. Lewis: The Riddle of Joy (Michigan: Wm. B. Eerdmans Publishing, 1989), 173-191.

Fernández Riquelme, Sergio, "«Tres acres y una vaca». El distribuismo o la radical opción moral de la economía contemporánea", Veritas, 26 (2012), 167-170, consultado el 4 de noviembre de 2017, http://dx.doi.org/10.4067/S071822732012000100008.

Fernández Sanz, Amable, "Utopía, progreso y revolución como categorías explicativas en la historia del pensamiento", Anales del Seminario de Historia de la Filosofía, 12 (1995), 165-189.

González Camargo, Javier Nicolás, “Topía y cronía de lo utópico y lo ucrónico Recuentos y valoraciones entre la literatura y la filosofía", Prometeica-Revista de Filosofia y Ciencias, 2 (2010), 5-21.

Goodwin, Barbara y Keith Taylor, The Politics of Utopia. A Study in Theory and Practice (Oxford: Peter Lang, 2009).

Gray, John, Anatomía de Gray (Barcelona: Paidós, 2011).

Herrera Guillén, Rafael, Breve bistoria de la utopia (Madrid: Ediciones Nowtilus, 2013).

Hoffman, John y Paul Graham, Introduction to Political Concepts (Harlow: Pearson Education Limited, 2006).

Kateb, George, Utopia and Its enemies (Nueva York: Schocken 1972).

Kumar, Krishan, Utopia \& Anti-utopia in Modern Times (Oxford: Basill Blackwell, 1991).

Kumar, Krishan, Utopianism (Buckungham: Open University Press, 1991). 
Manuel, Frank E. y Fritzie P. Manuel, Utopian Thought in the Western World (Cambridge: The Belknap Press of Harvard University Press, 1979).

Molina Álvarez de Cienfuegos, Ignacio, Conceptos fundamentales de Ciencia Política (Alianza Editorial: Madrid, 1998).

Moro, Santo Tomás, Utopía (Madrid: Editorial Tecnos, 2006).

Mumford, Lewis, The Story of Utopias (Nueva York: Boni and Liveright, 1922).

Pearce, Joseph, Escritores conversos. La inspiración espiritual en una época de incredulidad (Madrid: Palabra, 2009).

Pearce, Joseph, G. K. Chesterton. Sabiduría e inocencia (Madrid: Ediciones Encuentro, 2011), edición Kindle.

Sada Castaño, Daniel, Gilbert Keith Chesterton y el distributismo inglés en el primer tercio del siglo XX (Madrid: Fundación Universitaria Española, 2005).

Sargent, L. T., "The Three Faces of Utopianism Revisited”, Utopian Studies, vol. 5, 1 (1994), 1-37.

Sargent, L. T., "Utopian Traditions: Themes and Variations" en Schaer, R., Claes, G. y Sargent, L. T. (eds.), Utopia. The search for the ideal Society in the western world (Nueva York, Oxford University Press, 2000), 8-17.

Scruton, Roger, The Palgrave Macmillan Dictionary of Political Thought (Hampshire: Palgrave Macmillan, 2007).

Scruton, Roger, Conservative Texts. An Anthology (Hampshire: MacMillan, 1991).

Vega Rodríguez, Pilar, "Chesterton y Maeztu ante la utopía quijotesca”, Espéculo. Revista de Estudios Literarios, $\mathrm{n}^{\circ}$ 38, mazo-abril 2008, consultado el 29 de abril de 2016, https://pendientedemigracion.ucm.es/info/especulo/numero38/chesmaez.h tml.

Vega Rodríguez, "El regreso de don Quijote de Chesterton. Tradición y utopía”, Anales Cervantinos, vol. XXXVII (2005), 239-251.

Recibido: 27 de marzo de 2017

Aprobado: 29 de septiembre de 2017 